\title{
EL HÉROE FRENTE A LA PRECEPTIVA EN EL QUIJOTE
}

Cuando don Quijote sale a los caminos de la Mancha felizmente iluminado por una obsesiva lectura de novelas de caballería emprendía un viaje del que su fiel historiador Cide Hamete Benengeli no le permitiría regresar. Una vez que el ingenioso hidalgo se hace texto no vale al protagonista morir recuperando una cordura breve sobre su entorno para redimirse de su destartalada peripecia; ya se han fijado en el cuerpo de la novela todas sus chifladuras. Alonso Quijano se retracta de todas las locuras y en su lecho de muerte declara: «Pueda con vuestras mercedes mi arrepentimiento y mi verdad volverme a la estimación que de mí se tenía, y prosiga adelante el señor escribano* '. Ese señor escribano, notario de las voluntades y de los hechos, no puede, como Alonso desea, sustraerse a la ficción fundadora del moribundo, y tras éste expirar comenta kque nunca había leído en ningún libro de caballerias que algún caballero andante hubiese muerto en su lecho tan sosegadamente y tan cristiano como don Quijotew (II, 591). Alonso Quijano y don Quijote quedan para siempre confundidos en la novela de Cervantes, son un ente inseparable: las aventuras del loco caballero surgen de la imaginación que el ingenio aguzado del humilde hidalgo de la Mancha impone sobre su realidad cotidiana.

Semejante convivencia en el protagonista obliga al resto de los personajes a relacionarse activa o pasivamente con las fantasías de quien es centro de la novela y, obligados a participar o a dirigir la imaginación del loco, han de proponer argumentos para evitar ser manipulados en las historias de los demás. Si a la consecuente

1 Miguel de Cervantes, El ingenioso hidalgo don Quijote de la Mancha, ed. Luis Andrés Murillo. Madrid, Editorial Castalia, 1987, II, p. 590. Toda cita posterior referirá esta edición. 
complejidad de los niveles narrativos y a la variada habitación de las fábulas en ellos añadimos los diferentes autores que están tras el texto, hemos de destacar que tal complejidad apunta a una implícita y particular interpretación, tanto de El arte poética aristotélica introducida por Pinciano en su Philosophia antigua poética en 1596, nueve años antes de la publicación de la primera parte de nuestra novela, como de la Agudeza y arte de ingenio que Gracián publicara en 1648, veintitrés años después de la segunda parte ${ }^{2}$. Tanto el texto de 1596 como el de 1648 establecen una continuidad referencial con respecto a la preceptiva clásica destacando aspectos diferentes de ella, y por lo tanto, ni en el texto del Pinciano, ni en el de Gracián, ni en la novela cervantina, podremos hablar de ruptura, sólo de diferente interpretación en torno a un mismo y constante asunto: la representación en la literatura.

Que el Quijote se sitúe entre las obras mencionadas del Pinciano y de Gracián inmediatamente nos lleva a establecer en la novela elementos que corresponden a una evolución de los postulados renacentistas y a una prefiguración de los gustos barrocos. Y aunque no deja de ser legítimo este empeño, hemos de considerar que la singularidad que hace de la novela el punto inaugural de la modernidad de un género coloca su significación más allá del lugar de transición que su cronología evidencia. Nos serviremos de la fantasía que se adueña de Alonso Quijano y que lo transforma en caballero para observar el logro también heroico de la novela como renovación de un género y creación de una nueva forma de escritura en libertad ${ }^{3}$.

En las Anotaciones de F. de Herrera a las églogas de Garcilaso, o en el Cisne de Apolo de Luis Alfonso de Carballo late la idea de la escritura como épica. Según Herrera, en España no faltan caballeros heroicos sino escritores sabios que los inmortalicen, según Carballo la decadencia histórica se origina con el divorcio entre las armas y las letras. Para éste, tal decadencia ha de supe-

2 Sobre la relación de la Philosophia antigua poética con la obra de Cervantes ver JEAN-FrançoIs CANNAVAGgio «Pinciano y la estética literaria de Cervantes en el Quijote en Anales cervantinos, VII, 1958, pp. 13-107. Sobre los modelos de caballerías, y la polémica de Torquato Tasso y Ariosto acerca del papel de los episodios en el cuerpo de la obra ver ALBAN K. Forcione wIntroduction y uImitation and Innovation* en Cervantes' Christian Romance. Princeton University Press, 1972. pp. 3-63. E. C. RILEY en "Literary Theory in Action* también se ocupa de la teoria en el Renacimiento confrontando el canon clásico con el género popular uromanzo" italiano, y en "Inner and Outer Worldsw. contempla el cambio que se da en el Renacimiento de la epistemología de la autoridad a la de la experiencia, Don Quijote (London, Allen \& Unwin, 1986). Sobre el pensamiento cristiano de Cervantes y su relación con los decretos de la Contrarreforma ver ENRIOUE MORENO BAEZ, «Perfil ideológico de Cervantes» en Suma cervantina, ed. J. B. Avalle-Arce y E. C. Riley. London, Tamesis Books Limited, 1973, pp. 233-272.

" Para una aproximación al texto partiendo de la consideración de Ortega y Gasset de la critica como upotenciar la obra queridaw ver de LUIS ROSALES, Cervantes y la libertad. Madrid, Ediciones Cultura Hispánica, 1985. 
rarse por medio de la Poesía, que luchará contra el vicio y la ignorancia, para aquél, rescatar la memoria de personajes principales es labor heroica de una literatura inaugural. Cervantes logra ambos objetivos transformando las fantásticas aventuras de caballería en las locuras de un habitante de la Mancha. Alonso Quijano alcanza la inmortalidad que le hará subsistir «siglos infinitos, para gusto y general pasatempo de los vivientes" (II, 339), y sus proezas, a pesar de surgir de una imaginación enfermiza, quedarán para siempre insertas en la historia de la literatura. Destacando la heroicidad en lo cotidiano, más allá de sus modelos, el humilde hidalgo accede a la grandeza de los fantásticos caballeros imponiendo sus hazañas sobre el mundo real que le rodea.

El trastrueque que efectúa Alonso Quijano al convertirse en don Quijote sobre las convenciones de la novela de caballerías dice mucho de la actitud de la novela frente a las preceptivas. La deliberada lejanía de Don Quijote de cualquier modelo literario no puede dejarse pasar como un logro fortuito de una mente creadora. Cervantes reflexionó sobre su texto como sin duda lo corrobora la fe de erratas que aparece en la segunda parte. Sabemos que Cervantes estaba muy consciente de la necesidad de que la obra se mantuviese una a través de sus variados espisodios. A ello se debe que Cide Hamete Benengeli justifique la presencia de la historia del «Capitán cautivo" y la del "Curioso impertinente" recurriendo a la imprescindible variedad para hacer a una obra amena, ya que kel ir siempre atenido el entendimiento, la mano y la pluma a escribir de un solo sujeto y hablar por las bocas de. pocas personas era un trabajo incomportable... [y a la continuación afirma que] por huir deste inconveniente había usado en la primera parte del artificio de algunas novelas" (II, 366). Sin embargo, y a pesar de la claridad con que aparece el deseo de unidad, de la segunda parte comenta que «no quiso ingerir novelas sueltas ni pegadizas, sino algunos episodios que lo pareciesen, nacidos de los mesmos sucesos que la verdad ofrecew (II, 366), y considera que este esfuerzo por evitar digresiones es por el que la verdadera historia merece la mayor alabanza, es decir, nno por lo que escribe, sino por lo que ha dejado de escribir" (II, 367).

Hay una tendencia a la variedad y un freno consciente de ella en la pluma del autor. Lo que no se escribe es objeto de loa, pues al autor silenciar aventuras tangentes a la figura del hidalgo hace un esfuerzo considerable por evitar la dispersión. La estrategia para introducir en la novela la discusión teórica viene avalada por el origen literario de la locura del protagonista. Sin embargo, conviene distinguir lo que en la ficción se discute, de la novela en sí como práctica de la escritura y como producto terminado. En la novela destacamos los prólogos y los señalados segmentos de autocomentario - que más arriba hemos denominado ufe de erratas»- como los elementos más cercanos al pensamiento de Cervantes. 
La discusión teórica se refiere especialmente al concepto de unidad y variedad, y al problema de la verosimilitud. En la discusión del canónigo y el cura aquél dice «que son perjuidiciales los libros de caballerías... porque... cuál más, cuál menos, todos ellos son una misma cosa... cuentos disparatados... [que huyen] de la verosimilitud y de la imitación... [y que] llevan intención a formar una quimera o un monstruo que a hacer una figura proporcionada" (I, 564-65). Cide Hamete, como ya hemos indicado, también se hace eco de este dilema, y opta en la segunda parte por ceñir el relato a sucesos directamente relacionados a la figura de don Quijote. Sin embargo, se ha de admitir que la variedad está presente en ambas partes aunque en la segunda un sector importante de ella viene ocupado por la narración alternada en capítulos del gobierno de Sancho en la ínsula Barataria, y de la estancia de don Quijote en el palacio de los duques. Se ha relacionado la variedad con el Examen de ingenios para las ciencias de Juan Huarte de San Juan ${ }^{4}$. A la metáfora aristotélica que superpone la imagen de la unidad del cuerpo a la obra literaria para que ésta, «al modo de un viviente sin mengua ni sobra" se dirija "a una acción total y perfecta que tenga principio, medio y fin" se le enfrenta la del doctor Huarte que considera el equilibrio de la persona fruto de un desbalance de las tres facultades del ánima racional: memoria, entendimiento, e imaginativa ${ }^{5}$. Igualmente podemos oponer al aristotélico "la hermosura consiste en proporción y grandeza" (43) la importancia que en la Agudeza Gracián da a diferentes tipos de variedad. Así el discurso quinto sobre «la agudeza de improporción y disonancia", o afirmaciones como "la mezcla de proporción e improporción hace una armonía agradable" o "cuanto más sublime y realzada fuere la erudición, será más estimada; pero no ha de ser uniforme, ni homenaje, ni toda sacra, ni toda profana, ya la antigua y la moderna, una vez un dicho, otra un hecho de la historia, de la poesía; que la hermosa variedad, es un punto de providencia" son ejemplos claros de una valoración explícita de la belleza en la desproporción ${ }^{\circ}$.

Don Quijote cree en las novelas de caballería a pies juntillas, pero la imitación literal que, merced a su locura, de ellas hace, las

- Mary Gaylord Randel relaciona la variedad en el Quijote con la preponderancia que en el Examen de ingenios para las ciencias de Juan Huarte de San Juan se le da a la imaginativa, facultad cercana a la locura y hacedora de estructuras fantásticas. "Cervantes' Portraits \& Literary Theory in the Text of Fiction» en Cervantes vi.1, 1986, pp. 57-80.

s Aristóteles, El arte poética. México, Espasa Calpe, 1981, p. 73. Toda cita posterior se referirá a esta edición.

- Agudeza y arte de ingenio. Madrid, Espasa Calpe, 1957, pp. 41, 345. Toda cita posterior se referirá a esta edición. Para una visión contextual de la figura y obra de Gracián ver José ENRIQUe GIL LAPLANA "Gracián y su época” en Insula, 497, 1987, p. 7. Para el lugar de la variedad en la obra de Gracián ver AuRORA EGIDO "La variedad en la Agudeza de Gracián" en Syntaxis 16-17, 1988, pp. 49-61. 
limita al mundo natural de las llanuras de la Mancha. Tal aveniencia a los condicionantes de la naturaleza es lo que da verosimilitud en la novela de Cervantes a las fantasías de las novelas de caballería. Con el recurso de la locura Cervantes se ciñe a la realidad histórica y resuelve el aserto aristotélico de que "más vale elegir cosas naturalmente imposibles, con tal que parezcan verosímiles, que no las posibles, si parecen increíbles" (77) combinando ambas opciones en favor de la verosimilitud, pues lo imposible en el Quijote viene siempre incluido dentro de la naturaleza de un perturbado.

La novela de caballerías entra así a formar parte de la novela cervantina como transpolación de la figuración imaginativa del protagonista sobre la realidad evidente que le rodea. La novela de Cervantes es una novela verosímil, y aunque por las locuras de don Quijote veamos las alucinaciones de las novelas de caballería, siempre Alonso Quijano estará presente para afirmar que no hay caballería sino en la locura, que no hay hazañas sino la risible figura de un pobre hidalgo manchego figurado caballero.

El texto cumple con el requisito de verosimilitud propugnado por Aristóteles y sus seguidores renacentistas. El protagonista loco es esencialmente veraz, pues sus alucinaciones son concebidas de antemano como falsas para la percepción que el entendimiento tiene de la realidad circundante. Este ceñir los sucesos fantásticos a la imaginación del protagonista produce la verosimilitud y evita "los conceptos por ficción" de que trata el discurso XXXV de la Agudeza y arte de ingenio. Gracián contempla la posibilidad de expresar un concepto a través de "una invención fabulosa de algún suceso o algún dicho ajeno, para con ella exprimir bien el sentimiento, aumentando con lo fingido la ponderación (233). Los segmentos que cuentan aventuras de don Quijote en las que hay hechos fantásticos bien se pueden adscribir a esta idea graciana de la ponderación del concepto en la narración de hechos fabulosos, pero en el Quijote como novela estos hechos fantásticos son explícitamente introducidos como tales, diferenciándolos así de la verdadera historia del hidalgo, cosa que no sucede en los ejemplos con que Gracián ilustra su idea, pues en ellos se silencia todo autocomentario sobre el estatus de lo fantástico. Lo primero que sabemos cuando don Quijote sale de su pueblo es que lo que se viene es la interpolación de las fantasías sobre la realidad. Nunca dejaremos de entender que lo fantástico de don Quijote siempre es la locura de Alonso Quijano. En esta combinación de lo histórico y lo ficticio en la figura del protagonista hay una conciliación absoluta de la realidad y la fantasía, y una solución al problema de la introducción de hechos fantásticos sin menoscabo de la verosimilitud.

Pero que esta verosimilitud cumpla su función dentro del esquema trastocado de una novela de caballerías implica, además de la conciliación mencionada, una valoración especial de la pre- 
sencia del ingenio en la creación artística. Encontramos esclarecedor el consejo que en el prólogo a la primera parte la voz del amigo propugna: «a la llana, con palabras significantes, honestas y bien colocadas, salga vuestra oración y período sonoro y festivo, pintando, en todo lo que alcanzáredes y fuere posible, vuestra intención" (I, 58). Edwin Williamson ve en esta declaración un concepto de imitación distinto del aristotélico, pues no se ciñe a una acción histórica o a la experiencia cotidiana, y evita el camino hacia la referencialidad que hacía a la validez del discurso literario condicional a su capacidad para denotar las cosas del mundo externo ?.

Suscribimos la primacía de este "pintar la intención" como la forma de escritura que destaca la libertad como el soporte principal de la creación literaria, si bien la importancia que en el Quijote tiene el debate de los conceptos aristotélicos de representación nos obliga a ver el principio de "pintar la intención" a la luz de una particular interpretación de los mismos postulados aristotélicos.

El vínculo con Aristóteles en ninguna medida lo consideramos una fijación incómoda a unas reglas, al contrario, en la «intención» cervantina está la idea de representar el mundo físico circundante sobre el que nuestro caballero impone sus locuras como la mejor forma de acabar con las quimeras caballerescas. Y es que el pintar los conceptos libremente pasa en la novela de Cervantes por la práctica de reducir las inverosímiles aventuras de los caballeros a los condicionantes efectivos que la naturaleza impone sobre ellos. Que don Quijote arremetiendo gigantes sea volteado por las aspas del molino es una imagen novedosa pues concilia con verosimilitud las maravillas de la caballería con la mentalidad de un perturbado. La convivencia de la libertad creativa y la representación histórica la encontramos en la conciencia cervantina de que tal conciliación es uno de los logros principales de su obra, logro que por ser novedoso, es también maravilloso: La declaración orgullosa que don Quijote hace de sí cuando se presenta ante don Diego de Miranda es noticia explícita de que su figura "por ser tan nueva y tan fuera de las que comúnmente se usan, no me maravillaria yo de que le hubiese maravilladon (II, 151). Nueva maravilla ésta, que sin dejar de ser veraz suscita la admiración de los espectadores.

De igual forma que en el escrutinio de la biblioteca de Alonso Quijano se dice de Los cuatro de Amadis de Gaula que es el primer libro ede caballerías que se imprimió en España, y todos los demás han tomado origen y principio deste... [y que] es el mejor de todos los libros que de este género se han compueston (I, 110), don Quijote extrañado de su enjaulamiento tiene consciencia

7 "The Break with Romance: Don Quixote's Madness" en The Half-Way House of Fiction. Oxford, Clarendon Press, 1984, p. 86. Ver también del mismo autor 'Intención' and 'invención' in the Quixoten en Cervantes, VIII, 1, 1988, pp. 7-22. 
de la originalidad de su reducción, y la considera aportación novedosa al género de caballerías, y renovación que bien puede ser principio canónico de una nueva concepción de aventura pues «la caballería y los encantos destos nuestros tiempos deben de seguir otro camino que siguieron los antiguos" (I, 557). El protagonista se da cuenta de que su peripecia no se adecúa al modelo literario que guía sus pasos por los campos de la Mancha, y encuentra la explicación en la remodelación que tal género debe sufrir en los tiempos modernos. Más allá de la risible figura de nuestro escuálido personaje hay en el pertinaz y ridículo empeño de emular las antiguas hazañas de los caballeros andantes un gesto heroico paralelo al ejercicio literario de Cervantes que se rebela ante la tradición para establecer una escritura inaugural que combina ingeniosamente la fantasía con la realidad.

La renovación en el Quijote incluye el deseo de elevar la lengua castellana a la altura de los ejemplos clásicos utilizando un estilo que dé «a entender [los] conceptos sin intricarlos ni escurecerlos" (I, 58). Don Quijote se equivoca al suponer el comienzo de la escritura de sus hazañas en el estilo épico: «apenas había el rubicundo Apolo tendido por la faz de la ancha y espaciosa tierra las hermosas ebras de sus hermosos cabellos...» (I, 80). En este sentido, cuando don Quijote escoge el término culto «eructar" al "regoldar" utilizado por Sancho, se acerca más al deseo de Herrera de que ha de apartarse "este rústico miedo de nuestro animo; sigamos el exemplo de aquellos antiguos varones, que enriquecieron el sermón Romano con las vozes Griegas i peregrinas i con las barbaras mesmas" ${ }^{8}$. Preocupación ésta por renovar el castellano que está bastante alejada de la oscuridad tan alabada por Gracián y que él consideraba como una forma de elevación del placer y del concepto tratado pues «cuanto más escondida la razón, y que cuesta más, hace más estimado el concepto, despiértase con el reparo la atención, solicítase la curiosidad, luego lo exquisito de la solución desempeña sazonadamente el empeñon (48).

Si en cuanto a la valoración de la oscuridad no se aviene don Quijote con Gracián porque el hidalgo aconseja dar a entender los conceptos "sin intricarlos ni escurecerlos", y aunque hemos ya visto la preocupación constante en el Quijote por la unidad tan cara a los neoaristotélicos, cabe señalar que, como obra terminada, la novela de Cervantes participa más de la importancia que a la variedad se le concede en el Barroco que en el Renacimiento. Gracián afirma que «es anómalo el humano gusto, que apetece un mismo manjar mil diferencias de sainetes de los Poetas", y aconseja que aquél que aspire a la inmortalidad ha de procurar kcensurar como Tácito, ponderar como Valerio, reparar como Floro, propor-

- Obras de Garcilaso de la Vega con Anotaciones de Fernando de Herrera ed. Antonio Gallego Morell. Madrid: Consejo Superior de Investigaciones Científicas, 1973, p. 573. 
cionar como Patérculo, aludir como Tulio, sentenciar como Séneca" $(361,363)$.

En el Quijote se acepta la variedad de estilo, pero no la oscuridad, porque ésta va reñida con el carácter democrático que hace del Quijote una novela moderna. Las leyes van a la zaga de las costumbres. Cuando Gracián escribe su Agudeza las tendencias que en su texto se desgranan sistemáticamente tienen práctica inveterada. Aunque Gracián parece cuidarse de citar la obra de Cervantes, esto no es ningún obstáculo para encontrar las relaciones evidentes que hay entre ambas, en especial en lo que se refiere a la belleza en la desproporción y a la necesidad de la variedad. Gracián concede importante valor en su discurso «De la docta erudición y de las fuentes de que se sacan a las fuentes populares, pues "hasta los adagios y refranes valen mucho" (346), y muestra gran aprecio en su discurso "De los conceptos por acomodación de verso antiguo, de algún texto o autoridad" por las fuentes clásicas, siempre que en la cita autorial haya conveniencia *con la materia presente, [por] saberla aplicar con especial gracia y donosidad" (228). El mayor o menor grado de acuerdo del Quijote con la preceptiva neoaristotélica no significa una ruptura con sus postulados y una adhesión en la práctica de la escritura con los gustos barrocos posteriores. En el Quijote hay una nueva interpretación de la preceptiva aristotélica que equidista tanto de Pinciano como de Gracián.

El ingenioso hidalgo don Quijote de la Mancha se desprende de las normas vigentes de su época en la medida que adelanta los valores que el barroco destacará, pero no se somete a la prevalencia de uno u otro modo de considerar la creación artística. La novela de Cervantes se establece entre el Renacimiento y el Barroco y marca una diferencia que inaugura la novela moderna haciendo de la libertad el fundamento trascendente para que el artista cree sus objetos. De los neoaristotélicos se distingue sobre todo por destacar la importancia de la variedad tanto de estilo como de estructura, de Gracián en el rechazo de la oscuridad como fuente de placer.

El sentido democrático del Quijote está estrechamente vinculado a la comedia nueva de Lope y a su voluntad de satisfacer a un vasto público más allá de toda limitación preceptiva. A pesar de que el cura pide mayor censura para las comedias en su conversación con el canónico, afirma que su finalidad es kasí el entretenimiento del pueblo como la opinión de los ingenios de España" (I, 572), y defiende la conveniencia de su recepción en todos los estamentos sociales. Encontramos la originalidad de Cervantes tanto en la preeminencia de la libertad en el acto de creación como en la consideración de un público variado como destinatario de la obra de arte.

Al final, Cide Hamete dice a su pluma que queda «satisfecho y ufano de haber sido el primero que gozó el fruto de sus escritos 
enteramente, como deseaba, pues no ha sido otro mi deseo que poner en aborrecimiento de los hombres las fingidas y disparatadas historias de los libros de caballerías, que por las de mi verdadero don Quijote van ya tropezando, y han de caer del todo, sin duda alguna» (II, 593). El historiador está seguro de que Don Quijote inaugura una nueva forma de novelar que terminará poco a poco con los viejos usos de caballerías. Sin desprenderse de las preocupaciones aristotélicas presentes en el Renacimiento y en el Barroco Cervantes conforma un texto que sobrevivirá a la presencia que en él hay de los condicionantes de su tiempo. La escritura cervantina que calificamos de heroica ha conseguido "el mesmo crédito que suelen dar los discretos a los libros de caballerías" (I, 604) sin daño a la verosimilitud. La realidad toma cuerpo en el Quijote como maravilla porque en la realidad Cervantes encuentra todos los resortes de la variedad y los elementos necesarios para que la recepción de su texto acapare la atención de todos los componentes de la sociedad más allá de los confines de su siglo.

José MARRERo HenRÍQUeZ 